\title{
Small Bowel Bleeding Associated with Meckel's Diverticulum. Complex Diagnosis with Monoballoon Enteroscopy
}

\author{
Jonatán Mendoza Ramírez ${ }^{1 *}$, Diego Angulo Molina ${ }^{1}$, Javier García \\ Guerrero $^{2}$, Jorge Santín Rivero ${ }^{3}$ and Laura Montserrat Bernal López ${ }^{4}$ \\ ${ }^{1}$ Advanced Endoscopy Unit, ABC Medical Center Observatorio Campus, México \\ ${ }^{2}$ Department of Internal Medicine, ABC Medical Center Observatorio Campus, México \\ ${ }^{3}$ Deparment of General Surgery, Colon and Rectum. ABC Medical Center Santa Fe \\ Campus, México \\ ${ }^{4}$ Department of Surgical Pathology, ABC Medical Center Observatorio Campus, México \\ *Corresponding Author: Jonatán Mendoza Ramírez, Advanced Endoscopy Unit, \\ ABC Medical Center Observatorio Campus, Mexico City, México.
}

DOI: $10.31080 /$ ASGIS.2020.03.0157

\begin{abstract}
Meckel's diverticulum is a congenital diverticulum, which contains intestinal mucosa and ectopic tissue (gastric or pancreatic). The diagnostic accuracy of monoballoon enterosocopy has been reported between 58 - 74\% compared to $67 \%$ of the endoscopic capsule in the evaluation of evident small bowel bleeding. Meckel's diverticulum is rarely diagnosed in adults and is usually associated with complications such as gastrointestinal bleeding, obstruction and diverticulitis (30\%). The treatment for symptomatic Meckel's diverticulum is surgical resection, with or without an adjacent bowel segment.
\end{abstract}

Keywords: Diagnosis; Diverticulum; Enteroscopy; Bleeding

\section{Abbreviations}

OGB: Obscure Gastrointestinal Bleeding; EC: Endoscopic Capsule; DAE: Device-Assisted Enteroscopy; SBB: Small Bowel Bleeding; OH: Obscure Hemorrhage; MD: Meckel's Diverticulum; NSAIDs: Non-Steroidal Anti-Inflammatory Drugs

\section{Introduction}

Identifying the site of bleeding from the digestive tract may be a challenge in the practice of the gastroenterologist [1]. The most common etiologies of small bowel bleeding (SBB) are vascular lesions such as angioectasias, Dieulafoy lesions and hemangiomas;
Received: July 02, 2020

Published: July 28, 2020

(C) All rights are reserved by Jonatán

Mendoza Ramírez., et al. 
We report a case where gastrointestinal bleeding presented in a young man as an emergency with Meckel's diverticulum finding by monoballoon enteroscopy.

\section{Case Report}

A 26-year-old male presented to the emergency room with an history of hematochezia. In 2012, the presence of hematochezia was noted, initially attributed to duodenal ulcer secondary to consumption of non-steroidal anti-inflammatory drugs (NSAIDs), mainly ketorolac and diclofenac; the symptoms improved following conservative treatment with proton pump inhibitor and sucralfate. In 2017, hematochezia reappears 4 times, after ketorolac intake and a hemoglobin value dropped to $7.6 \mathrm{~g} / \mathrm{dL}$. Many studies were done (gastroscopies, colonoscopies and enteroscopies anterograde and retrograde) without an active bleeding site identified. One endoscopic capsule with no diagnostic conclusion and two negatives angiotomographies were done. He was admitted at the ABC Medical Center Observatorio Campus in 2018, with a new episode of hematochezia; an abdominal angiotomography was performed, which report a segment of small bowel with segmental dilation (Figure 1) and a scan with Technetium-99 marked erythrocytes negative for active gastrointestinal bleeding.

A retrograde monoballoon enteroscopy was done (Figure 1) in which a stenosis was visualized, due to concentric ulcer located $70 \mathrm{~cm}$ from the ileocecal valve, with fibrin base and just adjacent to a diverticulum. A tattoo of the area was performed for surgical identification (Figure 1); and some biopsies of the region were taken with report of intense acute ulcerated ileitis with granulation tissue, negative for neoplasm and microorganisms. Finally, a diagnostic laparoscopy was done and finding the Meckel's diverticulum (Figure 2) with intestinal resection and with mechanical latero-lateral anastomosis. The final histopathological report was a diffuse gastric mucosal heterotopia in diverticular wall (Figure 2). The patient evolved favorably, currently asymptomatic in his follow-up by external consultation.

The uniqueness of this report lies in the diagnostic challenge of small bowel bleeding associated with Meckel's diverticulum, which was possible only with monoballoon enteroscopy.

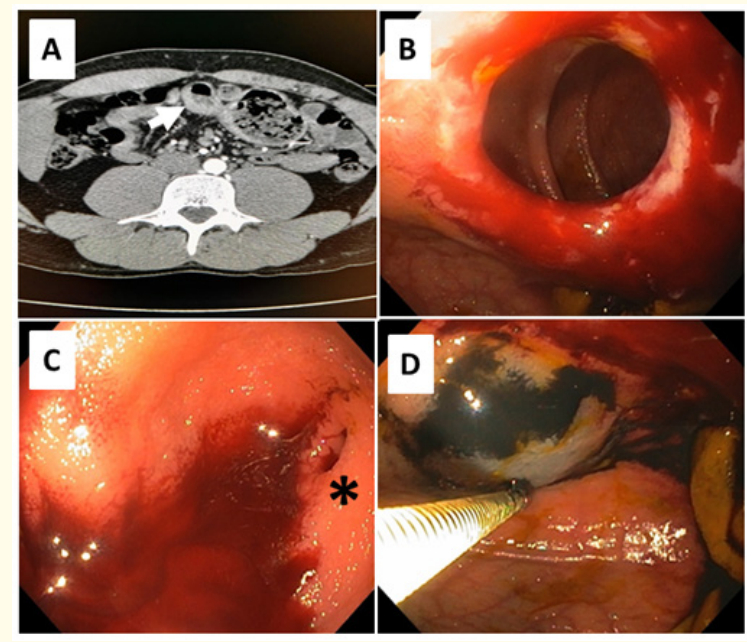

Figure 1: A) Contrast tomography of the abdomen. Segment of small intestine with segmental dilation (white arrow). B) Retrograde enteroscopy. Stenosing concentric ulcer $70 \mathrm{~cm}$ from ileocecal valve $\mathrm{C}$ ) Diverticulum orifice (black asterisk) adjacent to ulcerated area D) Marking of the area with tattoo.

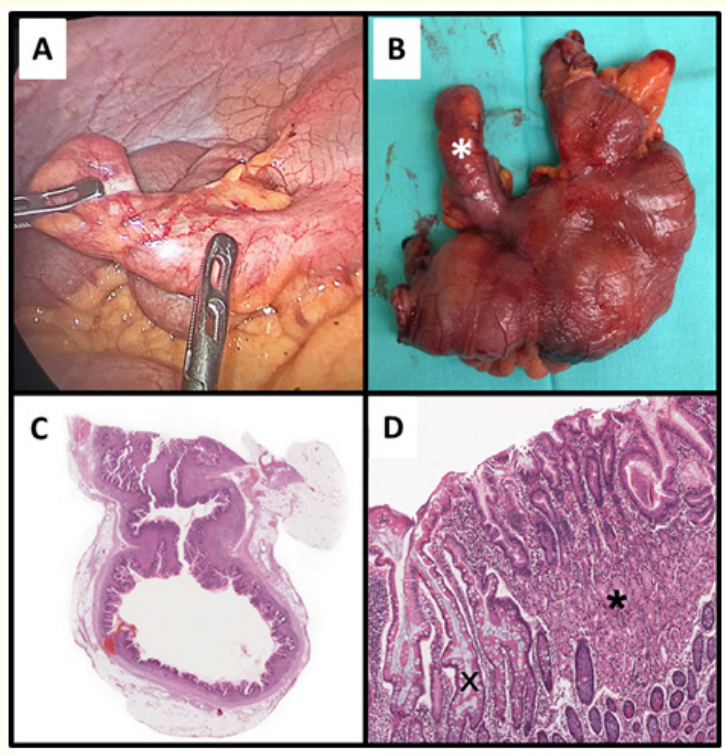

Figure 2: Surgical findings. A) Laparoscopy with Meckel's diverticulum identified B) Macroscopic photograph of Meckel's diverticulum (white asterisk) and ileum segment. C) Panoramic photomicrography of the diverticulum. D) Epithelial transition of duodenal mucosa $(\mathrm{X})$ with gastric mucosa (black asterisk). 


\section{Discussion}

Traditionally, an obscure gastrointestinal bleeding (OGB) is diagnosed when upper endoscopy and colonoscopy are not diagnostic and gastrointestinal bleeding or iron deficiency anemia persist. It is considered that $5-10 \%$ of bleeding is secondary to OGB. In 40 - 75\% of OGB cases, new technologies such as endoscopic capsule (EC), device-assisted enteroscopy (DAE) and tomography can identify an intestinal origin. Therefore, the term OGB has been replaced with the term "small bowel bleeding" (SBB). The term obscure hemorrhage $(\mathrm{OH})$ is reserved for cases where it is not possible to identify the bleeding site, even after small intestine studies have been done. Small bowel bleeding is defined as a hemorrhage from the gastrointestinal tract located between the Vater ampulla and the ileocecal valve [1].

Meckel's diverticulum is often asymptomatic and is fortuitously discovered during a surgical procedure or imaging study. It is known as the "great simulator" and can be responsible for a wide variety of symptoms. In many cases, complementary studies have little value when the diverticulum is not complicated. Ultrasound has a limited use and the contrast tomography could not diagnose MD, which can be mistaken as an intestinal loop [4]. In case of suspicion, the endoscopic capsule may show the MD orifice, but cases of capsule retention have been reported inside the diverticulum. Technetium 99 scan can detect gastric mucosa and allow a successful diagnosis, with a sensitivity and specificity of 85 and $95 \%$ respectively [5].

During childhood, gastrointestinal bleeding and obstruction are the most common complications of MD. Bleeding is related to the ulceration of the ileal mucosa adjacent to the acid-secreting ectopic gastric mucosa in almost all cases. In a retrospective study of 100 children with MD, the authors propose that the high production of acid in males promotes prevalence in this genre, with an increased risk for peptic ulcers in men where non-obstructive symptoms were the most prevalent [6]. In adults, bleeding is the initial symptom in 8 to $63 \%$ of patients with symptomatic MD. Arteriography can detect the diverticular origin of the hemorrhage, visualizing a dense arc corresponding to the parenchyma of the ectopic gastric mucosa [3]. Endoscopic capsule (EC) has better diagnostic yield in the context of digestive hemorrhage, compared to the angiotomography or mesenteric angiography, but in unstable patients angiography is preferred [2].
Device-assisted enteroscopy (DAE) allows therapeutic intervention in SBB. García-Correa., et al. mentioned that the most common indication for double-balloon enteroscopy was evident small bowel bleeding with diagnostic certainty of 65.2\% [7]. Double balloon and monoballoon enteroscopy are equivalent in procedure time, insertion depth, diagnostic and therapeutic achievement, and complication rate [8].

MD is rarely diagnosed in adults. There is no consensus on ideal management, best approach, and surgery when MD is discovered incidentally. Moreover, a symptomatic MD requires surgery [3].

\section{Conclusion}

In conclusion, the diagnosis of the etiology of small bowel bleeding represents a challenge. Direct observation of the diverticulum can be done by enteroscopy. Meckel's diverticulum identification may be a finding and diagnostic laparoscopy should not be ruled out as a last resource. The technetium-99m study is the most useful method for diagnosing Meckel's diverticulum, however, the use of enteroscopy made it possible to determine the origin of gastrointestinal bleeding in our unit.

\section{Conflict of Interest}

There is no financial interest or conflict of interest.

\section{Bibliography}

1. Kuo Jean R., et al. "The Clinician's Guide to Suspected Small Bowel Bleeding". The American Journal of Gastroenterology 114.4 (2019): 591-598.

2. Chetcuti Zammit Stefania and Reena Sidhu. "Small bowel bleeding: cause and the role of endoscopy and medical therapy". Current Opinion in Gastroenterology 34.3 (2018): 165-174.

3. Lequet J., et al. "Meckel's diverticulum in the adult". Journal of Visceral Surgery 154.4 (2017): 253-259.

4. Elsayes Khaled M., et al. "Imaging manifestations of Meckel's diverticulum". AJR: American Journal of Roentgenology 189.1 (2007): 81-88.

5. Sagar Jayesh., et al. "Meckel's diverticulum: a systematic review". Journal of the Royal Society of Medicine 99.10 (2006): 501-505.

6. Huang Chen-Chuan., et al. "Diverse presentations in pediatric Meckel's diverticulum: a review of 100 cases". Pediatrics and Neonatology 55.5 (2014): 369-375. 
7. García-Correa JJE., et al. "Double-balloon enteroscopy: Indications, approaches, diagnostic and therapeutic yield, and safety. Early experience at a single center". Revista de Gastroenterologia de Mexico 83.1 (2018): 31-40.

8. Kim Tae Jun., et al. "Comparison of the Efficacy and Safety of Single- versus Double-Balloon Enteroscopy Performed by Endoscopist Experts in Single-Balloon Enteroscopy: A SingleCenter Experience and Meta-Analysis". Gut and Liver 11.4 (2017): 520-527.

\section{Assets from publication with us}

- Prompt Acknowledgement after receiving the article

- Thorough Double blinded peer review

- Rapid Publication

- Issue of Publication Certificate

- High visibility of your Published work

Website: www.actascientific.com/ Submit Article: www.actascientific.com/submission.php Email us: editor@actascientific.com

Contact us: +919182824667 